\title{
Newborn screening for congenital adrenal hyperplasia in Tokyo, Japan from 1989 to 2013: a retrospective population-based study
}

Atsumi Tsuji ${ }^{1}$, Kaoru Konishi², Satomi Hasegawa², Akira Anazawa², Toshikazu Onishi 1,3, Makoto Ono ${ }^{1}$, Tomohiro Morio ${ }^{1}$, Teruo Kitagawa ${ }^{2}$ and Kenichi Kashimada ${ }^{1,2^{*}}$

\begin{abstract}
Background: Congenital adrenal hyperplasia (CAH) cause life-threatening adrenal crisis. It also affects fetal sex development and can result in incorrect sex assignment at birth. In 1989, a newborn screening program for congenital adrenal hyperplasia (CAH) was introduced in Tokyo. Here we present the results of this screening program in order to clarify the efficiency of CAH screening and the incidence of CAH in Japan.
\end{abstract}

Method: From 1989 to 2013, a total of 2,105,108 infants were screened for CAH. The cutoff level for diagnosis of CAH was adjusted for gestational age and birth weight.

Results: A total of 410 infants were judged positive, and of these, 106 patients were diagnosed with $\mathrm{CAH}$, indicating a positive predictive value (PPV) of $25.8 \%$. Of the 106 patients, 94 (88.7 \%) were diagnosed with 21-OHD. Of these 94 patients, 73 were diagnosed with the salt wasting form, 14 with the simple virilising form and 7 with the nonclassical form (NC21OHD). The mean birth weight and gestational age were $3192 \pm 385 \mathrm{~g}$ and $38.9 \pm 1.38$ weeks. 11 out of 44 female patients were assigned as female according to their screening result.

Conclusions: These data suggest that the newborn screening in Tokyo was effective, especially for sex assignment and preventing fatal adrenal crisis. The incidence of $\mathrm{CAH}$ was similar to that measured in previous Japanese screening studies, and it was also similar to that of western countries. The incidence of NC21OHD in Japan in the present study was lower than that in western countries as previous studies reported. The screening program achieved higher PPV than previous $\mathrm{CAH}$ screening studies, which might be due to the use of variable cutoffs according to gestational age and birth weight. However, most of the neonates born at 37 weeks or less that were referred to hospital were falsepositives. Further changes are needed to reduce the number of false positive preterm neonates.

Keywords: Congenital adrenal hyperplasia, Newborn screening, 21-hydroxylase deficiency

\section{Background}

Congenital adrenal hyperplasia $(\mathrm{CAH})$ is an inherited disorder caused by the loss or severely impaired activity of steroidogenic enzymes involved in cortisol biosynthesis. More than $90 \%$ of cases result from 21-hydroxylase deficiency (21-OHD) caused by mutations in CYP21A2 [1, 2].

\footnotetext{
* Correspondence: kkashimada.ped@tmd.ac.jp

${ }^{1}$ Department of Pediatrics and Developmental Biology, Tokyo Medical and Dental University, Tokyo, Japan

${ }^{2}$ Tokyo Health Service Association, Newborn Screening, Tokyo, Japan

Full list of author information is available at the end of the article
}

The prevalence of 21-OHD has been estimated at 1 in 18,000 . According to the clinical phenotypes, the disease is classified into three forms, the salt wasting (SW) form and the simple virilising (SV) form, which are also called the classical form, and the nonclassical (NC) form. The SW form is the severest. Virilisation of external genitalia in newborn females and precocious puberty due to overproduction of androgens from the adrenal cortex are major clinical problems of both the SW and SV forms. In the SW form, in addition to overproduction of androgens, 
aldosterone is deficient and it causes life-threatening adrenal crisis.

In order to prevent life-threatening adrenal crisis and to help make the appropriate sex assignments in affected female patients, newborn mass screening programs for $\mathrm{CAH}$ have been introduced in many countries including Japan [3-5]. The aim of our study was to summarize the results of the past 23 years of newborn mass screening for $\mathrm{CAH}$ in Tokyo. Specifically, we wished to determine the efficiency of $\mathrm{CAH}$ screening and the incidence of $\mathrm{CAH}$ in Tokyo.

This study is the largest retrospective analysis of $\mathrm{CAH}$ newborn screening by using a single screening program in East Asia [6-10]. Tokyo is the largest city accounting for more than $10 \%$ of the population in Japan [11], and to date, more than two million neonates have been screened. False positives for $\mathrm{CAH}$ in preterm infants is one of the major concerns of newborn screening programs [2]. In a pilot study from 1984 to 1987 , we found that we could reduce the number of false positives by using higher cut-offs for preterm or low birth weight infants from that for term infants, and used these different criteria throughout the screening program.

The positive predictive value of our study was higher than those of previous reports of $\mathrm{CAH}$ screenings.

\section{Methods}

\section{Subjects}

From 1 January, 1989 to 31 March, 2013, neonates born in Tokyo were screened. Basically we recommended collecting the blood sample from the age of 4 to 7 days, and clinical data was obtained by followup survey from each hospital where neonates judged as positive at screening were referred.

\section{Measurement of 17-OHP and criteria}

Blood samples were collected by a heel prick blotted on a filter paper after written informed consent was obtained from parents. The level of 17hydroxyprogesterone (17-OHP) was initially determined by enzyme linked immunosorbent assay (ELISA) (Siemens Medical Solutions Diagnostics, CA, U.S.) without steroid extraction. Blood samples in the 97th percentile or higher of 17-OHP values were subjected to the second ELISA (Eiken Chemical CO., LTD, Tokyo, Japan) after steroid extraction (Fig. 1). The measured values on the second assay were doubled to be equivalent to the serum levels. Sex, birth weight, and gestational age were recorded in the application form for the screening test, so we obtained these data from all neonates who underwent the screening. The cutoff level of 17-OHP was adjusted according to 1) gestational age (GA) at birth, 2) corrected gestational age at the time of the test and 3) body weight at the time of the test (Table 1). The cutoffs were determined according to our pilot study of serum 17-OHP levels in term and preterm infants. The criteria for preterm and low birth weight infants were used from the start of the screening in Tokyo. The algorithm and criteria of the screening are shown in Table 1 and Fig. 1. Briefly, the patients whose results were "re-tests" were recalled to repeat a test of 17-OHP measurement, and the test was performed at the hospital where the patients were born. If the level of 17-OHP was higher than $60 \mathrm{nmol} / \mathrm{L}$ or still higher than normal range on the third test, the patient was considered to be positive. The patients with "positive" results were referred to pediatric endocrinologists for further endocrinological evaluation.

\section{Follow-up survey}

We performed follow-up survey of the patients who were referred to hospitals. We collected clinical information of the patients from the physicians of the hospitals. The collected information included the diagnosis of the patients including the type of $\mathrm{CAH}$, laboratory data before the start of the treatment (17$\mathrm{OHP}, \mathrm{Na}, \mathrm{K}$ ), and the brief clinical course during the early infantile period. We gathered the surveys of all patients who were referred to the hospitals. The present retrospective analysis was approved by the ethics committee of Tokyo Health Service Association (No. 2014-2-1).

\section{Results}

Firstly, we comprehensively analysed our data, including the incidence and the positive predictive value (PPV) of the screening. Subsequently, we examined the clinical details of the $\mathrm{CAH}$ patients who were identified by our screening, and finally, one of the purposes of the screening, sex assignment issue, was analysed.

\section{Incidence and positive predictive value of the screening}

A total of 2,105,108 neonates were screened. Coverage of the screening was $93 \%$ of newborn babies in Tokyo registered in Vital Statics of Japan [12]. Of these, 410 neonates had positive results and were referred to hospitals. The median age at first screening was 5 days (range 0-62 days), consistent with our recommendation. Of the 410 neonates, 106 were diagnosed with $\mathrm{CAH}$, resulting in an incidence of 1:19,859 (Table 2). Diagnosis of CAH was based on the endocrinological data and physical findings [13]. Genetic tests were not carried out in all cases. 


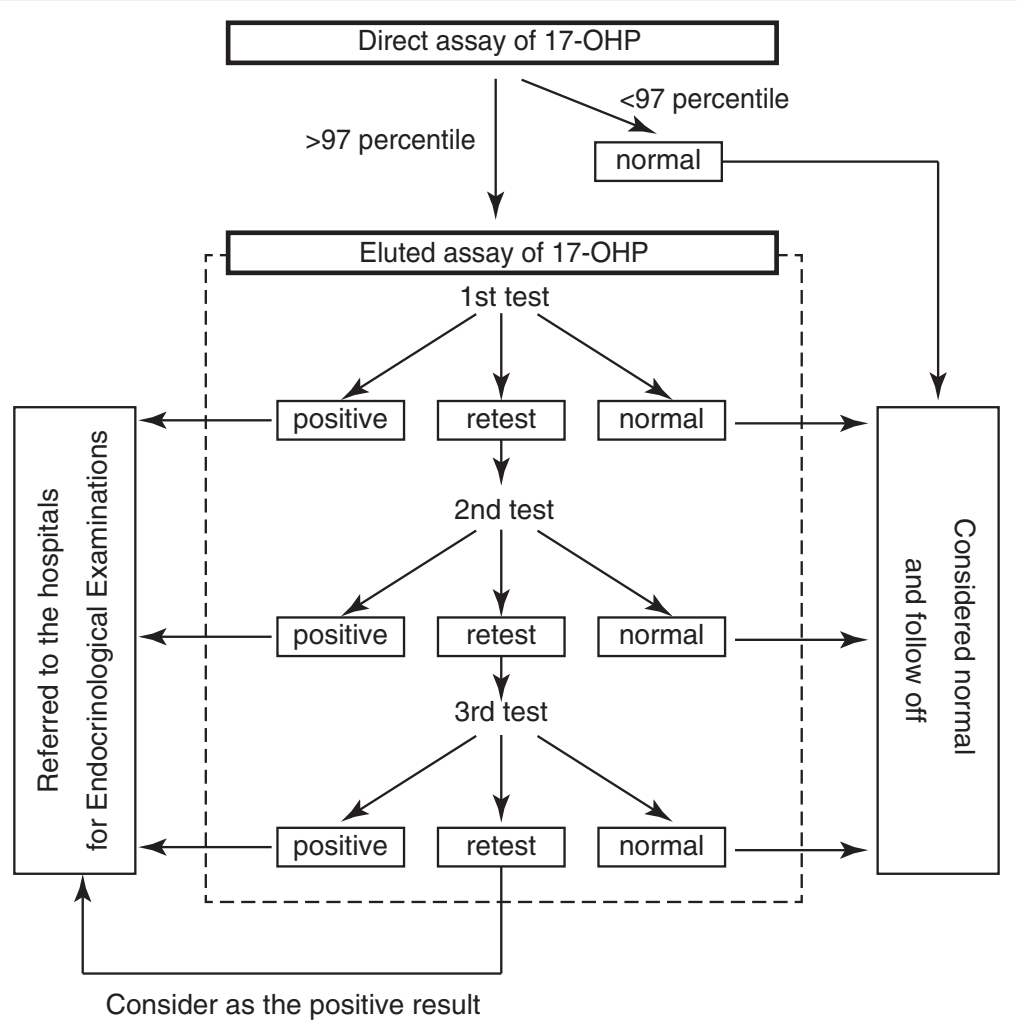

Fig. 1 Algorithm of CAH screening in Tokyo. Abbreviation: 17-OHP: 17-hydroxyprogesterone

Of 300 infants born at term, 100 were diagnosed as having $\mathrm{CAH}$, resulting in a positive predictive value (PPV) of full-term neonates of $33.3 \%$. Even though the criteria were applied according to gestational age, $99(24.1 \%)$ were preterm infants with a positive result. Thus, the PPV of preterm neonates who were born before 37 weeks gestation was only $2 \%(2 / 99)$, resulting in $25.8 \%(106 / 410)$ of the total PPV of the screening (Table 3).
The gestational age of the 21-OHD patients was distributed in a bell-shape curve with a single peak (Fig. 2), however, the gestational age distribution in the referred neonates showed two peaks at 39 and 37 weeks, resulting in lower predictive value of the screening for infants born at 37 weeks gestation or before. These data suggest that neonates, even at 37 weeks of gestational age, tend to show unspecific elevation of serum levels of 17-OHP by cross-

Table 1 Criteria of CAH mass screening in Tokyo

\begin{tabular}{|c|c|c|c|c|c|}
\hline \multicolumn{6}{|c|}{$<$ Criteria according to the gestational age $>$} \\
\hline 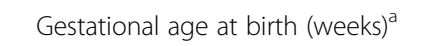 & & $\leq 29$ & $30-34$ & $35-36$ & $37-$ \\
\hline Corrected gestational age (weeks) ${ }^{b}$ & & $\leq 31$ & $32-35$ & $36-37$ & $38-$ \\
\hline \multicolumn{6}{|l|}{$<$ Criteria according to weight $>^{c, d}$} \\
\hline Body weight (g) & & $\leq 999$ & $1,000-1,999$ & $2,000-2,499$ & $2,500-$ \\
\hline \multirow[t]{2}{*}{ Cutoff level of 17-OHP [nmol/L] } & Retest $^{e}$ & 60 & 45 & 24 & 15 \\
\hline & Positive ${ }^{f}$ & & 60 & 60 & 60 \\
\hline
\end{tabular}

\footnotetext{
a Samples collected before the age of 7 days
}

${ }^{\mathrm{b}}$ Samples collected at the age of 7 days or after

$\mathrm{c}^{1 \text { st }}$ test: Body weight $=$ Birth weight. $2^{\text {nd }}$ test and after: Body weight $=$ Corrected body weight calculated by the formula as below. Corrected body weight at test (g) $=$ birth weight $(\mathrm{g})+$ (age at test -7$) \times 20(\mathrm{~g})$

${ }^{d}$ For infants born small or large for gestational age, either the criteria of gestational age (corrected gestational age) or body weight was applied, whichever was lower value

erecall for the second (or the third) test of the screening

frefer to hospitals for further endocrinological examinations 
Table 2 Positive predictive value of the screening and incidence of $\mathrm{CAH}$ in Tokyo. Overview of the screening results

\begin{tabular}{ll}
\hline Category & Number (Percent) \\
\hline Total infants tested & $2,105,108(100)$ \\
Retested & $7,940(0.38)$ \\
Positive & $410(0.02)$ \\
CAH patients & $106(0.005)$ \\
Positive predictive value & $25.8 \%$ \\
Incidence of CAH by screening & $1: 19,859$
\end{tabular}

reaction for adrenal steroids from fetal adrenal cortex (Fig. 2).

\section{Clinical details of CAH patients identified by the screening}

The gestational ages and the birth weights were $38.9 \pm$ 1.38 weeks and $3192 \pm 385 \mathrm{~g}$ (Table 4). In 2009, the average birth weight of single births in Japan was $3020 \mathrm{~g}$, and the incidence of preterm births was $4.7 \%$ [14], which are not significantly different from those of the 21-OHD patients in Tokyo.

Two preterm neonates were diagnosed with 21-OHD. Both were born at 36 weeks and their birth weights were $2570 \mathrm{~g}$ and $2770 \mathrm{~g}$, respectively. None of the 21-OHD patients were born before 36 weeks. Only one patient was born as low birth weight infant with $2380 \mathrm{~g}$ at 40 weeks.

Information on the type of $\mathrm{CAH}$ was available for 96 patients in the survey. All but two of these patients had 21-OHD. In addition, two of these patients had $3 \beta$ hydroxysteroid dehydrogenase deficiency. The most frequent type of 21-OHD was the salt wasting form, accounting for 73 of the 94 patients. Fourteen of the 21OHD patients had the simple virilising form and seven had the nonclassical forms. The incidence of nonclassical forms was low, approximately 1:300,729 as reported previously in Japan [15-17].

The mean values of the levels of 17-OHP on the first test in SW, SV and NC were 676.5, 146.3, and $29.2 \mathrm{nmol} /$ L, respectively (Fig. 3). Although these values were

Table 3 Positive predictive value of the screening and incidence of $\mathrm{CAH}$ in Tokyo. Positive predictive value on term and preterm infants

\begin{tabular}{|c|c|c|c|c|}
\hline & Total & Term & $\begin{array}{l}\text { Preterm } \\
\text { (<37 weeks) }\end{array}$ & $\begin{array}{l}\text { Data not } \\
\text { available }\end{array}$ \\
\hline & \multicolumn{4}{|c|}{ Number of infants } \\
\hline $\begin{array}{l}\text { Infants with } \\
\text { positive result }\end{array}$ & 410 & 300 & 99 & 11 \\
\hline CAH patients & 106 & 100 & 2 & 4 \\
\hline $\begin{array}{l}\text { Positive predictive } \\
\text { value }\end{array}$ & $25.8 \%$ & $33.3 \%$ & $2.0 \%$ & \\
\hline
\end{tabular}
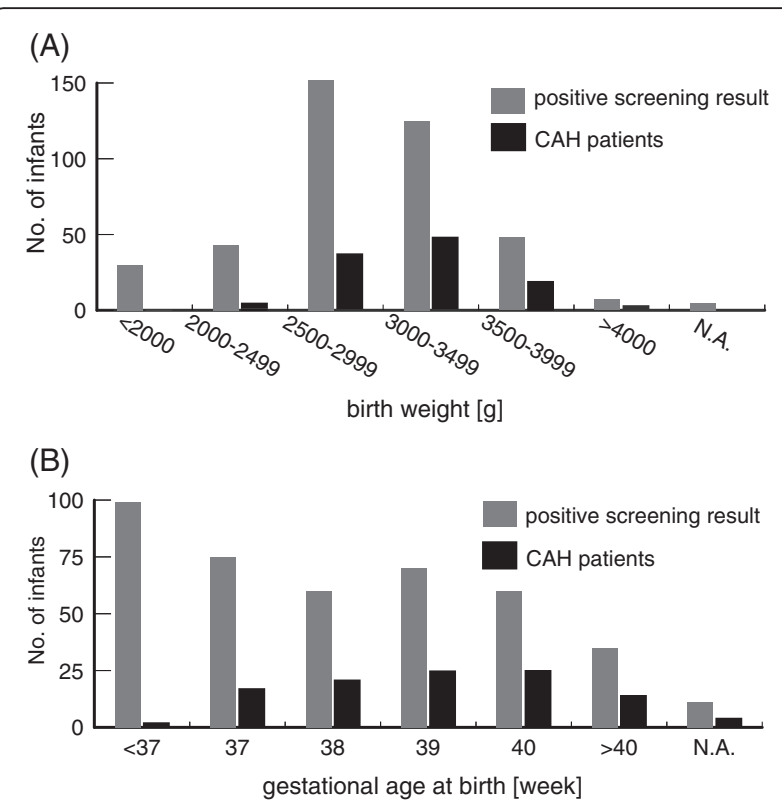

Fig. 2 Birth weights (a) and gestational ages (b) of patients and newborns judged as positive in $\mathrm{CAH}$ screening. Abbreviation: $\mathrm{CAH}$ : congenital adrenal hyperplasia; N.A.: data not available

Table 4 Clinical characteristics and the details of the screening of $106 \mathrm{CAH}$ patients. Characteristics of $106 \mathrm{CAH}$ patients

\begin{tabular}{|c|c|c|c|}
\hline & Number & & Percent \\
\hline \multicolumn{4}{|l|}{ Sex } \\
\hline Male & 56 & & (52.8) \\
\hline Female & 44 & & $(41.5)$ \\
\hline Changed from male to female & & 2 & \\
\hline Assigned to female by screening & & 9 & \\
\hline Data not available & 6 & & \\
\hline \multicolumn{4}{|l|}{ Gestational Age } \\
\hline Preterm (<37 weeks) & 2 & & (1.90) \\
\hline Term & 100 & & $(94.3)$ \\
\hline Data not available & 4 & & \\
\hline \multicolumn{4}{|l|}{ Form of $\mathrm{CAH}$} \\
\hline 21-OHD & 94 & & $(88.7)$ \\
\hline Salt Wasting (SW) & & 73 & \\
\hline Simple Virilising (SV) & & 14 & \\
\hline Nonclassical (NC) & & 7 & \\
\hline $3 \beta-H S D D$ & 2 & & (1.89) \\
\hline Data not available & 10 & & \\
\hline Gestational Age [weeks] (Mean \pm SD) & $38.9 \pm 1.38$ & & \\
\hline Birth weight $[g]$ (Mean \pm SD) & $3192 \pm 385$ & & \\
\hline
\end{tabular}


significantly different, they substantially overlapped, suggesting that it is inappropriate to predict the form of $\mathrm{CAH}$ according to the value of 17-OHP.

On the first test, most SW patients (94.5\%) showed remarkably elevated levels of 17-OHP, and were referred to hospitals (Table 5). While, four SW patients (Nos. 53, 84, 99, 101) showed mildly elevated levels of 17-OHP on the first test (Table 6) and required repeated tests. These results suggest that mildly elevated 17-OHP does not exclude the possibility of classical 21OHD. On the other hand, none of the NC patients were discovered on the first test, suggesting that it is not likely to be the NC form of 21-OHD (NC21OHD) whose 17-OHP was remarkably elevated on the first test (Table 5). No fatal cases were reported by followup survey.

\section{Screening-assisted sex assignments}

Of the $106 \mathrm{CAH}$ patients, 56 were males, 44 were females and the information of the sex in 6 cases was not available on the survey (Table 4). Two of the patients originally thought to be males were reassigned as females according to the screening results. Nine patients were assigned as females according to the screening results (Table 4).

If the patients without information of assigned sex were female with ambiguous genitalia, the total number of female patients might be 50 , and the sex assignment of 17 female patients would have been assisted by the screening results.

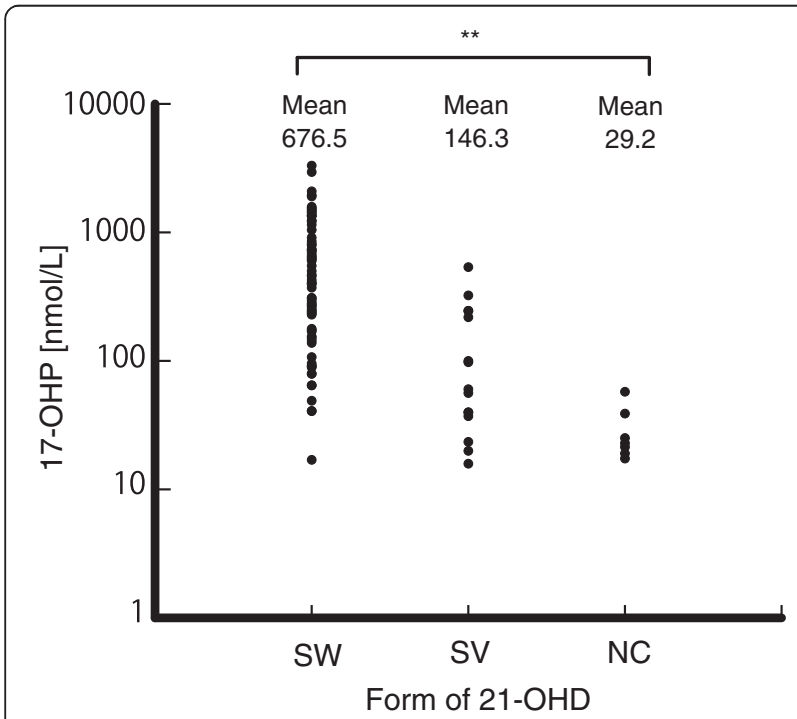

Fig. 3 Serum levels of 17-OHP in CAH patients at the first tests. Abbreviation: 17-OHP: 17-hydroxyprogesterone; 21-OHD: 21hydroxylase deficiency; SW: salt wasting; SV: simple virilising; NC: nonclassical. ${ }^{*}, p<0.01$ (ANOVA)
Table 5 Clinical characteristics and the details of the screening of $106 \mathrm{CAH}$ patients. The number of tests to be assessed positive in each form of $21-\mathrm{OHD}$

\begin{tabular}{lllll}
\hline $\begin{array}{l}\text { Number } \\
\text { of test }\end{array}$ & $\begin{array}{l}\text { SW } \\
(n=73)\end{array}$ & $\begin{array}{l}\text { SV } \\
(n=14)\end{array}$ & $\begin{array}{l}\text { NC } \\
(n=7)\end{array}$ & $\begin{array}{l}\text { Total } \\
(n=94)\end{array}$ \\
\hline 1 & Number of patients (\%) & & \\
2 & $69(94.5)$ & $8(57.1)$ & $0(0)$ & $77(81.9)$ \\
$\geq 3$ & $3(4.11)$ & $3(21.4)$ & $2(28.5)$ & $8(8.51)$ \\
\hline
\end{tabular}

Upper: The number of the patients

Lower (\%): The proportion to the total number of patients in each form

\section{Discussion}

Our study revealed the incidence of CAH in Tokyo was $1 / 19,859$. In Japan, newborn screening has been carried out in each prefecture independently with different criteria and different follow-up survey systems. Thus, it has been difficult to have a large-scale study of the screening. Suwa's meta-analysis in Japan and Morikawa's analysis in Sapporo reported the incidence of $\mathrm{CAH}$ was $1 /$ 18,827 and $1 / 20,756[10,18]$. The incidences in these studies were very similar to our data. We assume that the incidence of $\mathrm{CAH}$ in Japan is approximately $1 /$ 20,000 .

Our data suggests that the screening was performed properly. One of the aims of the screening is to assist proper sex assignment in $46, \mathrm{XX}$ patients. It was reported that, before the neonatal screening program started, $12 \%$ of 46,XX patients were incorrectly assigned to male [19]. Therefore, our data strongly suggest that the screening assisted in the sex assignment of $\mathrm{CAH}$ patients.

The another objective of the screening is to prevent fatal adrenal crisis during the neonatal period. The screening program might contribute to decreasing the mortality by preventing neonatal fatal adrenal crisis with few false negative cases. Despite our screening program lacked the system to detect false negative patients, none of the cases who were missed by the screening program were reported to be fatal by pediatric endocrinologists in Tokyo. Additionally, no childhood deaths in recent years

Table 6 Clinical characteristics and the details of the screening of 106 CAH patients. 17-OHP values of SW patients tested repeatedly

\begin{tabular}{llll}
\hline & \multicolumn{3}{l}{ 17-OHP result $[\mathrm{nmol} / \mathrm{L}]$} \\
\cline { 3 - 4 } & First test & Second test & Third test \\
\hline Twice & & & \\
Patient No.53 & 49.09 & 339.97 & \\
Patient No.99 & 16.97 & 90.90 & \\
Patient No.101 & 40.60 & 244.22 & 23.94 \\
Three times & & & \\
Patient No.84 & 47.57 & 27.27 & \\
\hline
\end{tabular}


in Japan have been attributed to CAH [20]. Further, no mortalities from $\mathrm{CAH}$ have been attributed to false negatives after the start of newborn screening programs in Japan [21]. The screening programs have decreased mortality rate due to CAH from $6.8 \%$ to $1.2-4.0 \%$ [21].

Because CAH screening results in many false positives in preterm infants [2], we used cut-off criteria for preterm infants and low birth weight infants that were higher than those used for term infants. The recall ratio (0.19 \%) was lower and the PPV (25.8\%) was higher than those of other reports (Table 7) [5, 9, 10, 22-25], especially when compared to two other studies from Japan that did not use different cut-off criteria for preterm infants. Indeed, the ratio of the number of referred term infants to the number of preterm infants (3.03) was much higher than the ratios in other reports (Table 7), suggesting that our program eliminated false positive cases of preterm or low birth weight infants. We concluded that using cut-off criteria for preterm infants and low birth weight infants was effective at reducing false positive cases.

Even though our PPV was higher than the PPVs in other screening systems, it was still only $25 \%$, indicating that the efficiency of our screen program at eliminating false positive cases is limited. Unspecific cross-reactions for adrenal steroids from fetal adrenal cortex have been reported to cause false positive results in preterm infants [26]. The high false-positive rate is one of the major concerns of $\mathrm{CAH}$ newborn screening, and introducing novel assay systems with higher specificity for 17-OHP might achieve more efficient screening [27-29]. A recently developed assay system, that uses tandem mass spectrometry, has been reported to have extremely high specificity for steroid assays and might be considered for a future assay system [30, 31].

The incidence of NC21OHD patients identified by the screening was lower than the incidence in European countries and the U.S. $[4,25]$, and is consistent with previous reports from Japan [15-17]. It is difficult to predict the incidence of NC21OHD according to the newborn screening results because patients with the $\mathrm{NC}$ form are usually missed by newborn screening [32]. However, it has been assumed that the incidence of NC21OHD in Japan would be lower than that of western countries [16, 17]. In western countries, nonclassical cases are mainly caused by V281L mutation in CYP21A2 that is rare in Japanese patients $[1,16,33]$. In Japan, a P30L mutation is the major genetic cause for NC21OHD, although the frequency of P30L in Japan is much lower than that of V281L in western countries, resulting in a lower incidence of $\mathrm{NC} 21 \mathrm{OHD}$ in Japan [16].

In our study, two patients were diagnosed with $3 \beta$ HSDD, suggesting that a careful diagnostic approach is essential to differentiate other types of $\mathrm{CAH}$ from 21OHD. The serum level of 17-OHP is known to be elevated in other forms of $\mathrm{CAH}$, such as $11 \beta$-hydroxylase deficiency (11-OHD) and cytochrome P450 oxidoreductase deficiency (PORD). Even in $3 \beta-H S D D$, the 17-OHP level is reported to be paradoxically elevated, and occasionally similar to that of 21-OHD [34]. These diagnostic problems are potential clinical pitfalls in diagnosing the type of $\mathrm{CAH}$. Including sex assignment, a different clinical approach is required for each type of $\mathrm{CAH}$. In terms of the type of $\mathrm{CAH}$, it should be noted that 11OHD patients were not reported in our screening survey. The incidence of 11-OHD has been reported to be much higher than that of 3 $\beta$-HSDD, and we cannot exclude the possibility that some 11-OHD patients were incorrectly diagnosed.

The limitation of this study is lack of the system to collect the information on false negative cases and didn't detect precise number of false negatives.

\section{Conclusion}

Newborn screening in Tokyo was performed effectively for sex assignment and preventing fatal adrenal crisis, contributing to correct sex assignment and reduce mortality. The incidence of classical 21-OHD was similar to that of western countries, although the incidence of $\mathrm{NC}$

Table 7 Proportion of preterm infants among published studies

\begin{tabular}{|c|c|c|c|c|c|c|c|c|c|c|}
\hline \multirow[b]{2}{*}{ Reference } & \multirow[b]{2}{*}{$\mathrm{n}$} & \multicolumn{6}{|c|}{ Number of Patients Referred to Clinical Hospital } & \multirow[t]{2}{*}{ PPV, \% } & \multicolumn{2}{|c|}{ Variable 17-OHP cutoff criteria } \\
\hline & & \multicolumn{2}{|l|}{ Total (\%) } & \multirow{2}{*}{$\begin{array}{l}\text { Term } \\
\text { (A) } \\
\end{array}$} & \multirow{3}{*}{$\begin{array}{l}\text { Preterm } \\
\text { (B) } \\
150\end{array}$} & N.A. & $A / B$ & & $\overline{\mathrm{GA}}$ & Birth weight \\
\hline & & & & & & & & & & \\
\hline & $8 /, 827$ & $2 \angle 4$ & $.255)$ & 10 & & 4 & 0.47 & 5.9 & Yes & Yes \\
\hline France, 2012 [22] & $6,012,798$ & 15,407 & $(0.256)$ & 1,058 & 10,562 & 3,787 & 0.10 & 2.3 & No & No \\
\hline Sweden, 2014 [5] & $2,737,932$ & 1728 & $(0.063)$ & 874 & 854 & 0 & 1.02 & 13.4 & Yes & Yes \\
\hline Niigata, Japan, 2011 [9] & 478,337 & 242 & $(0.050)$ & 69 & 173 & 0 & 0.39 & 10.7 & No & No \\
\hline Sapporo, Japan, 2014 [10] & 251,922 & 880 & $(0.349)$ & 170 & 708 & 2 & 0.24 & N.A. & No & No \\
\hline Tokyo, Japan, 2015 & $2,105,108$ & 410 & $(0.019)$ & 300 & 99 & 11 & 3.03 & 25.8 & Yes & Yes \\
\hline
\end{tabular}

Abbreviation: PPV: Positive Predictive Value; GA: Gestational Age; N.A.: data not available 
was much lower than reported previously in western countries. The PPV appeared to be improved by adjusting the cutoffs for gestational age and for body weight, although the PPV for preterm infants was still low. To reduce the number of false positive cases, assay systems with higher specificity are needed.

\section{Abbreviations}

$\mathrm{CAH}$ : congenital adrenal hyperplasia; 17-OHP: 17-hydroxyprogesterone;

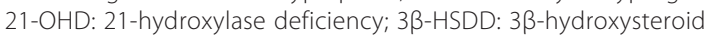
dehydrogenase deficiency; 11-OHD: 11ß-hydroxylase deficiency; PORD: cytochrome P450 oxidoreductase deficiency; PPV: positive predictive value; SW: salt wasting; SV: simple virilising; NC: nonclassical; NC21OHD: nonclassical form of 21-OHD; GA: gestational age.

\section{Competing interests}

The authors declare that they have no competing interests.

\section{Authors' contributions}

$\mathrm{KKO}, \mathrm{SH}, \mathrm{AA}$ and TK carried out analysis of the level of serum 17-OHP and follow-up survey as a neonatal screening program. KKo also summarized the screening data. AT, KKa participated in analysis of the data and drafted the manuscripts. KKa, MO, TO conceived of the study. KKa also participated in its design. TM supervised the study and drafting manuscript. All authors read and approved the final manuscript.

\section{Acknowledgements}

We thank all the doctors who answered the follow-up survey. We also thank to Drs Kazuhiko Shimozawa, Sumitaka Saisho, Takio Toyoura and Satomi Koyama for contributing to the screening program. The present study was supported by Inin-Keirikin which was entrusted by Japanese government for academic research.

\section{Author details}

'Department of Pediatrics and Developmental Biology, Tokyo Medical and Dental University, Tokyo, Japan. ${ }^{2}$ Tokyo Health Service Association, Newborn Screening, Tokyo, Japan. ${ }^{3}$ Kinki Central Hospital, Hyogo, Japan.

\section{Received: 1 December 2014 Accepted: 9 December 2015}

\section{Published online: 15 December 2015}

\section{References}

1. White PC, Speiser PW. Congenital adrenal hyperplasia due to 21-hydroxylase deficiency. Endocr Rev. 2000;21(3):245-91.

2. White PC. Neonatal screening for congenital adrenal hyperplasia. Nat Rev Endocrinol. 2009;5(9):490-8.

3. Padilla CD, Therrell BL. Newborn screening in the Asia Pacific region. J Inherit Metab Dis. 2007;30(4):490-506.

4. Therrell Jr BL, Berenbaum SA, Manter-Kapanke V, Simmank J, Korman K, Prentice $L$, et al. Results of screening 1.9 million Texas newborns for 21-hydroxylase-deficient congenital adrenal hyperplasia. Pediatrics. 1998:101(4 Pt 1):583-90.

5. Gidlof S, Wedell A, Guthenberg C, von Dobeln U, Nordenstrom A. Nationwide Neonatal Screening for Congenital Adrenal Hyperplasia in Sweden: A 26-Year Longitudinal Prospective Population-Based Study. JAMA Pediatr. 2014;168(6):567-74

6. Chu SY, Tsai WY, Chen LH, Wei ML, Chien YH, Hwu WL. Neonatal screening for congenital adrenal hyperplasia in Taiwan: a pilot study. J Formos Med Assoc. 2002;101(10):691-4.

7. Padilla CD, Therrell Jr BL, Working Group of the Asia Pacific Society for Human Genetics on Consolidating Newborn Screening Efforts in the Asia Pacific Region. Consolidating newborn screening efforts in the Asia Pacific region : Networking and shared education. J Community Genet. 2012;3(1):35-45

8. Kaur G, Srivastav J, Jain S, Chawla D, Chavan BS, Atwal R, et al. Preliminary report on neonatal screening for congenital hypothyroidism, congenital adrenal hyperplasia and glucose-6-phosphate dehydrogenase deficiency: a Chandigarh experience. Indian J Pediatr. 2010;77(9):969-73.
9. Nagasaki K, Asami T, Abe Y, Usuda T, Kikuchi T, Uchiyama M. The occurrence of neonatal acute respiratory disorders in 21-hydroxylase deficiency. Endocr J. 2011:58(7):603-6.

10. Morikawa S, Nakamura A, Fujikura K, Fukushi M, Hotsubo T, Miyata J, et al. Results from 28 years of newborn screening for congenital adrenal hyperplasia in sapporo. Clin Pediatr Endocrinol. 2014;23(2): $35-43$.

11. Vital, Health and Social Statistics Division, Statistics and Information Department, Minister's Secretariat, Ministry of Health, Labour and Welfare (2015): Summary tables of vital statistics: Japan, each prefecture and 21 major cities. e-stat; Portal Site of Official Statistics of Japan. [http://www.e-stat.go.jp/SG1/estat/CsvdlE.do?sinfid=000027231392]

12. Vital, Health and Social Statistics Division, Statistics and Information Department, Minister's Secretariat, Ministry of Health, Labour and Welfare (2015): Live Births in Tokyo, 1983-2013. e-stat: Portal Site of Official Statistics of Japan. [http://www.e-stat.go.jp/SG1/chiiki/ CommunityProfileTopDispatchAction.do?code=2]

13. Speiser PW, Azziz R, Baskin LS, Ghizzoni L, Hensle TW, Merke DP, et al. Congenital adrenal hyperplasia due to steroid 21-hydroxylase deficiency: an Endocrine Society clinical practice guideline. J Clin Endocrinol Metab. 2010;95(9):4133-60.

14. Vital and Health Statistics Division, Statistics and Information Department, Minister's Secretariat, Ministry of Health, Labour and Welfare : Live Births Specified Report of Vital Statistics in FY 2010. [http://www.mhlw.go.jp/ english/database/db-hw/FY2010/live_births.html]

15. Tajima T, Fujieda K, Nakae J, Mikami A, Cutler Jr GB. Mutations of the CYP21 gene in nonclassical steroid 21-hydroxylase deficiency in Japan. Endocr J. 1998;45(4):493-7.

16. Tajima T, Fujieda K, Nakae J, Toyoura T, Shimozawa K, Kusuda S, et al. Molecular basis of nonclassical steroid 21-hydroxylase deficiency detected by neonatal mass screening in Japan. J Clin Endocrinol Metab. 1997:82(7):2350-6.

17. Kashimada K, Ishii T, Nagasaki K, Ono M, Tajima T, Yokota I, et al. Clinical, biochemical, and genetic features of non-classical 21-hydroxylase deficiency in Japanese children. Endocr J. 2015;62(3):277-82.

18. Suwa S. Nationwide survey of neonatal mass-screening for congenital adrenal hyperplasia in Japan. Screening. 1994;3:141-51.

19. Suwa S, Igarashi Y, Kato K, Kusunoki T, Tanae A, Niimi K, et al. The clinical surveilance report of congenital adrenal hyperplasia - First chapter : Analysis about the prevalence. The Journal of the Japan Pediatric Society. 1981;85(2):204-10 [published in Japanese language].

20. Vital, Health and Social Statistics Division, Statistics and Information Department, Minister's Secretariat, Ministry of Health, Labour and Welfare (2015): Deaths by causes (the list of three-character categories), sex and age: Japan, 1995-2013. e-stat; Portal Site of Official Statistics of Japan. [http://www.e-stat.go.jp/SG1/estat/GL32020101.do]

21. Ogawa E, Fujieda K, Tachibana K, Inomata H, Kinoshita E, Kusuda S, et al. Mortality in Patients with Congenital 21-Hydroxylase Deficiency Diagnosed after the Introduction of a Newborn Screening Program in Japan. Clin Pediatr Endocrinol. 2003;12(1):19-23.

22. Coulm B, Coste J, Tardy V, Ecosse E, Roussey M, Morel Y, et al. Efficiency of neonatal screening for congenital adrenal hyperplasia due to 21 hydroxylase deficiency in children born in mainland France between 1996 and 2003. Arch Pediatr Adolesc Med. 2012;166(2):113-20.

23. Steigert M, Schoenle EJ, Biason-Lauber A, Torresani T. High reliability of neonatal screening for congenital adrenal hyperplasia in Switzerland. J Clin Endocrinol Metab. 2002:87(9):4106-10.

24. Van der Kamp HJ, Noordam K, Elvers B, Van Baarle M, Otten BJ, Verkerk PH. Newborn screening for congenital adrenal hyperplasia in the Netherlands. Pediatrics. 2001:108(6):1320-4.

25. Balsamo A, Cacciari E, Piazzi S, Cassio A, Bozza D, Pirazzoli P, et al. Congenital adrenal hyperplasia: neonatal mass screening compared with clinical diagnosis only in the Emilia-Romagna region of Italy, 1980-1995. Pediatrics. 1996:98(3 Pt 1):362-7.

26. al Saedi S, Dean H, Dent W, Stockl E, Cronin C. Screening for congenital adrenal hyperplasia: the Delfia Screening Test overestimates serum 17hydroxyprogesterone in preterm infants. Pediatrics. 1996;97(1):100-2.

27. Allen DB, Hoffman GL, Fitzpatrick P, Laessig R, Maby S, Slyper A. Improved precision of newborn screening for congenital adrenal hyperplasia using weight-adjusted criteria for 17-hydroxyprogesterone levels. J Pediatr. 1997; 130(1):128-33 
28. Nordenstrom A, Wedell A, Hagenfeldt L, Marcus C, Larsson A. Neonatal screening for congenital adrenal hyperplasia: 17-hydroxyprogesterone levels and CYP21 genotypes in preterm infants. Pediatrics. 2001;108(4):E68.

29. Sarafoglou K, Banks K, Gaviglio A, Hietala A, McCann M, Thomas W. Comparison of one-tier and two-tier newborn screening metrics for congenital adrenal hyperplasia. Pediatrics. 2012;130(5):e1261-8.

30. Janzen N, Peter M, Sander S, Steuerwald U, Terhardt M, Holtkamp U, et al. Newborn screening for congenital adrenal hyperplasia: additional steroid profile using liquid chromatography-tandem mass spectrometry. J Clin Endocrinol Metab. 2007;92(7):2581-9.

31. Lacey JM, Minutti CZ, Magera MJ, Tauscher AL, Casetta B, McCann M, et al. Improved specificity of newborn screening for congenital adrenal hyperplasia by second-tier steroid profiling using tandem mass spectrometry. Clin Chem. 2004;50(3):621-5.

32. Speiser PW. Nonclassic adrenal hyperplasia. Rev Endocr Metab Disord. 2009: 10(1):77-82.

33. Weintrob N, Brautbar C, Pertzelan A, Josefsberg Z, Dickerman Z, Kauschansky A, et al. Genotype-phenotype associations in non-classical steroid 21-hydroxylase deficiency. Eur J Endocrinol. 2000;143(3):397-403.

34. Simard J, Moisan AM, Morel Y. Congenital adrenal hyperplasia due to 3beta-hydroxysteroid dehydrogenase/Delta(5)-Delta(4) isomerase deficiency. Semin Reprod Med. 2002;20(3):255-76.

\section{Submit your next manuscript to BioMed Central} and we will help you at every step:

- We accept pre-submission inquiries

- Our selector tool helps you to find the most relevant journal

- We provide round the clock customer support

- Convenient online submission

- Thorough peer review

- Inclusion in PubMed and all major indexing services

- Maximum visibility for your research

Submit your manuscript at www.biomedcentral.com/submit 